\title{
The Order of Emergence of the Morphological Markers of Temporal Expression in the Croatian EFL Learners' Longitudinal Speech Production Data
}

\author{
Mirjana SEMREN \\ University of Split \\ E-mail: mdukic@ffst.hr
}

\begin{abstract}
This study addresses the acquisition of the morphological markers of temporal expression in the interlanguage of Croatian primary school learners of English as a foreign language (EFL). The acquisition of morphological markers was documented regarding the order of emergence of nine grammatical morphemes. The emergence of these morphemes was examined following the obligatory occasion analysis (R. Brown 1973) which identified the obligatory contexts for each morpheme and the number of their correct suppliance. The order of emergence was obtained by the group score method (H.C. Dulay/ M.K. Burt 1974) according to which the morphemes were ranked in decreasing order of accuracy. Additionally, the study documented the order of emergence of four verb tenses. The data collection period comprised three generations of Grade 8 learners thus yielding a total of 56 transcribed recordings. The learners' language samples were gathered via task-based activities. Although the findings displayed discrepancies in the ranking orders obtained for different generations of Grade 8 learners, the Spearman rank order correlations suggest that there seems to be a homogeneous order of emergence across three generations of the eighth graders. The results revealed not only that Present Continuous emerged after Simple Present but also showed that Present Perfect emerged after Simple Past.
\end{abstract}

Keywords: morphological markers, order of emergence, grammatical morphemes, verb tenses, obligatory occasion analysis

\section{Introduction}

The expression of temporality has proven to be an interesting area of study in the field of second language acquisition (SLA) not only because it is a fundamental category of human experience and cognition" (W. Klein et al. 1988: 73) but also because all human languages possess a rich variety of linguistic devices to convey it. The research in second language temporal expression originated from the morpheme-order studies in the 1970s which laid the foundation for further studies of the acquisition of tenseaspect morphology and its related temporal semantics. These studies were associated with two different linguistic traditions: the European and the North American tradition. Since the two traditions overlap as they both investigate the morphological means of temporal expression, the present study hopes to provide additional findings related to the emergent use not only of the morphological markers but also of the verb tenses in the developing interlanguages of the Croatian EFL learners. The first part of this paper provides a theoretical background for the study and is accompanied by an 
overview of the previous research whereas the obtained results are revealed in the final part of the paper.

\section{Theoretical background}

The history of research in the emergent tense-aspect system can be traced back to the studies known as the morpheme order studies in the 1970s. The starting point for the order of morpheme acquisition studies was a longitudinal study by W. Brown (1973) who inquired about the order of acquisition of 14 morphemes in the speech production of three American preschool children learning English as their first language (L1). His groundbreaking contribution in the field of L1 research was the concept of suppliance in obligatory context (SOC) which identified obligatory context "as a kind of test item which the child passes by supplying the required morpheme or fails by supplying none or one that are not correct" (W. Brown 1973: 255). As claimed by W. Brown (1973: 272 ), if the child was able to supply a morpheme at the $90 \%$ accuracy level in three consecutive recordings, that morpheme was considered to be acquired which led him to conclude that the order of acquisition was "amazingly constant across three unacquainted American children".

Partially replicating the research design introduced by W. Brown (1973), J. de Villiers and P. de Villiers (1973) undertook a cross-sectional study based on the spontaneous L1 speech data of 21 English speaking children. Namely, they refuted a $90 \%$ accuracy threshold imposed by W. Brown (1973) only to rank the morphemes according to the accuracy with which they were scored. The results of their study correlated significantly with W. Brown's (1973) results according to which the present participle was the first temporal morpheme to appear, the past irregular preceded the past regular which, in turn, was followed by the third person singular $-s$. Moreover, the order of emergence of Present Perfect and Past Perfect in both studies was not ranked due to the lack in the suppliance of the morphemes constituting these tenses. The findings from Brown's study (1973) supported by the findings of J. de Villiers and P. de Villers's study (1973) launched many future morpheme order studies from the perspective of second language (L2) acquisition.

A number of cross-sectional studies of L2 morpheme ordering revealed the same order for both children (H.C. Dulay/ M.K. Burt 1973) and adults (N. Bailey et al.1974): -ing, irregular past, third person singular $-s$. Later studies of L2 acquisition which investigated the order of both the past irregular and the past regular displayed some variation in their rank order. In some studies, the past regular preceded the past irregular (H.C. Dulay/ M.K. Burt 1974, J. Barrot/ K. de Leon 2014) whereas in other studies, the past irregular was placed before the past regular (S. Krashen 1977). D. Larsen-Freeman (1975) found even greater variation in terms of past regular versus past irregular ordering across various elicitation tasks among different L1 backgrounds. Longitudinal studies of L2 morpheme ordering supported the irregularbefore-regular order (K. Hakuta 1974, R. Dietrich et al. 1995). The overall results of these studies also pointed to other salient commonalities; the copula be preceded the auxiliary be (H.C. Dulay/ M.K. Burt 1973, N. Baileyet al. 1974, F. Behjat/ F. Sadighi 
2011) and additionally, both morphemes were ranked at the top along with the present participle (P. Widiatmoko 2008, U. F. Ibáñez 2013).

In the late 1970s, morpheme order research which accumulated a fair amount of evidence supporting the notion of "remarkably regular order of accuracy for English grammatical morphemes" (R. Ellis/ G. Barkhuizen 2005: 74) became more intrigued by diverse determinants accounting for L2 acquisition order (e.g. the learner's L1, the learner's age, the influence of different elicitation instruments, the effect of instruction). The shift in focus from the acquisition of morphology as form towards the acquisition of L2 temporal semantics began in the 1980s with the seminal studies of both European and American researchers.

European researchers (the meaning-oriented approach) investigated interplay of several means of temporal expression including pragmatic, lexical and morphological devices whereas American researchers (the form-oriented approach) primarily focused on the emergence of verbal morphology (K. Bardovi-Harlig 1999). European researchers opposed to the dominance of American grammar-oriented second language acquisition research, embedded their morphological emergence studies within the European Science Foundation Project-ESFP (R. Dietrich et al.1995). Therefore, the study findings to be presented onwards exclusively address the acquisition of the morphological markings of temporality being the reference point of both traditions.

The ESF longitudinal studies investigated the acquisition of morphological form in the tense-aspect system of both Romance and Germanic languages. In a longitudinal study of L1 Italian girls acquiring English verbal morphology, W. Klein (1995) reported the following order of emergence: third person singular $-s$, present tense copula, past irregular, present participle, Present Perfect, past regular, shall/will, Past Perfect. Additional longitudinal studies of the acquisition of English tense-aspect morphology were conducted by K. Bardovi-Harlig $(1997,2000)$ who reported similar results according to which the first to emerge is Simple Past followed by Past Progressive, Present Perfect and, finally, Past Perfect. Moreover, the order outlined in N. Bailey's (1987) cross-sectional study supported the previous findings that Simple Past precedes Past Progressive.

The ESF studies, along with other studies inquiring about the acquisition of tenseaspect morphological markers have identified four general properties regarding the emergence of verbal morphology (K. Bardovi-Harlig 2000). First, the acquisition of temporal expression is slow, gradual and continuous. Second, when a particular morpheme first appears it tends to be overused. Third, irregular morphology precedes regular morphology and fourth, verb with a verbal suffix seems to be acquired before the auxiliary verb in cases when the target form is comprised of an auxiliary and the verb with a verbal suffix.

The study of emergent systems of temporality has predominantly concentrated on the tense-aspect morphology referring to the past due to the fact that it occurs relatively early in interlanguage development and can be observed for majority of learners (K. Bardovi-Harlig 2000). However, the expression of futurity became the scope of a more recent study (K. Bardovi-Harlig 2004). Therefore, this study strives 
to bring closer the acquisition of not only the morphological markers referring to the expression of the past but of those markers referring to the expression of the present within the framework of the current analysis which, as previously indicated, opens with the acquisition of grammatical morphemes. Hopefully, a more insightful view into the order of emergence of multiple temporal expressions, past versus present, in the speech production of Croatian EFL learners might be revealed.

\section{Aims}

The present study attempted to answer the following research questions:

1. RQ1 What is the frequency of obligatory and correct suppliance in the use of morphological markers in the speech production of three groups of Croatian Grade 8 primary school learners during three years of research? How is the suppliance in obligatory contexts distributed across three groups of learners?

2. RQ2 What is the order of the emergence of morphological markers for each group of Grade 8 learners? What are the differences/similarities in the obtained orders of the emergence of morphological markers across three groups of Grade 8 learners?

3. RQ3 What is the order of the emergence of verb tenses in the interlanguage of Grade 8 learners?

\section{Methodology}

The following subsections summarize the methodology used to carry out the research.

\subsection{Participants}

A total number of 281 Grade 8 learners pertaining to three different generations, i.e. groups of Croatian EFL learners took part in this study over the course of three years of research. There were 86 learners participating in the first year (2008/2009), 116 learners in the second year (2009/2010) and 79 learners in the third year of research (2010/2011). All the participants had started their EFL study in the first grade since English is a compulsory school subject in Croatia. In accordance with the Creational national curriculum (Croatian Ministry of Science, Education and Sports 2011), Grade 8 learners completing primary school education are expected to reach CEFR A2 level (Council of Europe 2001).

Grade 8 learners were drawn from 5 primary schools. Two criteria for choosing the schools were applied. Firstly, the school in which the author was a former English language teacher, and secondly, those schools in which the author's fellow colleagues teach English as a foreign language. In both situations, not only the school headmaster and the learners but also the learners' parents were informed about the scope of the study and the data collection procedure. Finally, parental consent was provided orally during teacher-parent meetings.

\subsection{Sample}

During the observation period, 56 tape recorded samples of parts of EFL classroom dialogue were obtained ( 22 recordings in the first year, 21 recordings in the second 
year and 13 in the last year of research). The duration of each recording was approximately 15 minutes.

A predetermined plan established a longitudinal study for collecting oral samples including three sampling periods in each school year, i.e. the beginning, the middle part and the ending of a school year. These samples, however, were widely spaced in each year of research owing to unforeseen situations (e.g. school closed due to weather, insufficient number of learners due to illness). Furthermore, 2 out of 7 recordings accumulated at the end of the third year of research were accidentally erased from the tape recorder whereas the remaining 5 recordings were excluded from the sample partially due to their low quality and partially due to a substitute teacher not willing to participate in this study. As a result, as previously mentioned, only 13 recordings were obtained during the third year of the research study.

The classroom recording data were gathered by the English language teachers with the author taking notes on the learners' verbal production during the recording sessions. In this manner, accurate recordings of everything that was said were attained. Upon each recording session, the oral data were transcribed and checked against the tape recordings. For the purpose of this research, the author had developed her own notation symbols according to the guidelines provided by the transcription literature (J.A. Edwards 2001).

\subsection{Instrument}

The recorded samples cover different types of task-based activities (e.g. problemsolving activities, discussions, role-plays, activities starting with the same type of question, guessing games, stories) most of which were tailored from the research literature (P. Ur 1992, M. Parrot 1993, J. Harmer 2007). Some of the communicative activities were designed by the author while a smaller portion of these activities were designed from suggestions found on the Internet.

The content of these activities was revealed prior to the beginning of each recording session. As a result, the learners' speech production was entirely up to them, thus representing their authentic and spontaneous language use. However, whenever the learners refuted participating in a preplanned communicative activity, commonly due to lack of their interest, they were given the opportunity to choose a more appealing activity since participation in this study was voluntary.

\subsection{Selection and coding}

Nine morphological markers were selected in the transcribed samples of the learners' speech production data. The selected markers, frequently targeted in the morpheme acquisition literature, referred to the following morphemes: third person singular $-S$, auxiliary verb be, present participle -ing, past regular -ed, past irregular, auxiliary verb have, past participle -en, present tense copula be (am, are, is) and past tense copula be (was, were). The use of nine morphemes demonstrate the examples found in the transcripts:

- $\quad$ third person singular $-S$

It costs three thousand kunas. 
- $\quad$ auxiliary verb be

She thinks that he is cheating her.

- $\quad$ present participle -ing

Get out of here! I'm watching TV.

- past regular -ed

You need to hear what happened in school.

- past irregular

He went to the casino and then he spent a lot of money.

- auxiliary verb have

Have you ever been to a mall or a shopping centre?

- past participle -en

Have you ever taken money from your parents's wallet?

- $\quad$ present tense copula be (am, are, is)

My first problem is about TV.

- $\quad$ past tense copula be (was, were)

They were together in the room.

In addition, these morphemes were joined together to form four tenses: Simple Present, Present Continuous, Simple Past and Present Perfect. Simple Present was identified by the use of the third person singular and the present tense copula be while Present Continuous by the use of the auxiliary verb be and the present participle. Simple Past was identified by the use of the past regular, the past irregular and the past tense copula be. Finally, Present Perfect was identified by the use of the auxiliary verb have and the past participle.

The selected morphemes were examined with regard to their suppliance in obligatory context (R. Brown 1973). Although the SOC measure identified three different occurrences of morphemes in obligatory occasions, the markers expressing temporality in this study were only distinguished with regard to their obligatory and correct suppliance. The idea of slightly modifying the research method arose from the suggestions initiated by other researchers, i.e. D. Larsen-Freeman (1975) and K. Bardovi-Harlig (2000) who challenged the validity of the previous morpheme order findings.

Obligatory suppliance (OS) was identified as the occurrence of morphological markers in a context which required the presence of a particular morpheme. Correct suppliance (CS) of certain marker was identified as its occurrence in both the correct form and context. Obligatory and correct suppliance was coded for each marker. Obligatory suppliance was coded by counting the number of obligatory occasions for an individual morpheme with the correct suppliance being coded by counting the number of correct occurrences for the same morpheme. In the example $I$ went to shopping yesterday and I buy er some great er...yellow trousers, there were two obligatory contexts for the suppliance of the past irregular (went, bought). However, the occurrence of this marker was correctly supplied only once (went). Therefore, the occurrence of the past irregular was coded as two obligatory suppliances and one correct suppliance. 
Both obligatory and correct suppliances of the morphemes were coded for each learner in all the transcribed recordings across three years of research. A modified coding table originally developed by D. Larsen-Freeman (1975) was used in this study.

\section{Data analysis}

All the coded data were entered into Microsoft EXCEL spreadsheet tables for farther analyses. The statistical analyses were performed via SPSS programme package for Windows 17.0.

The analysis of the frequency of obligatory and correct suppliances in the use of morphological markers (RQ1) was based on the total number of their obligatory and correct occurrences. The total number of obligatory suppliance was determined by summing all coded obligatory occasions for a particular morpheme; the total number of correct suppliance was determined likewise, namely by summing all coded correct instances for that morpheme. The analysis was conducted in all the transcripts across three groups of learners.

The order of emergence of morphological markers (first part of RQ2) was established according to their accuracy scores. For each morpheme an accuracy score was calculated by the group score method (H.C. Dulay/ M.K. Burt 1974). The rank ordering method applied in this study was the one introduced by J. de Villiers and P. de Villiers (1973) who simply ranked the morphemes on the basis of the obtained accuracy scores. The reason for applying a slightly diverse ranking order method was to enable the comparis- on of the obtained findings with the results of the previous morpheme order studies. Furthermore, the group means method (H.C. Dulay/ M.K. Burt 1974) was additionally applied when determining the order of the emergence of morphological markers so as to reduce the effect of variability.

The comparison of the emergence orders of morphological markers as a prerequisite for determining their differences/similarities (second part of RQ2) across three groups of learners was performed by Spearman rank order correlations. The comparison was conducted only on the orders of emergence obtained by the group score method since it was the primary method of data analysis. Moreover, the same type of correlation was applied to compare the emergence orders obtained by both methods so as to verify the stability and validity of the attained results.

Due to a relatively small sample, the order of the emergence of verb tenses (RQ3) was determined by gathering the data on both obligatory and correct suppliances of the markers forming the tenses across three groups of Grade 8 learners into one sufficiently large sample size. Only the group score method was applied when establishing the emergent order of tenses.

\section{Results}

The results of the study findings are reported following the research questions. 


\subsection{Results on the suppliance and distribution of obligatory and correct ocurrences in the use of morphological markers}

\begin{tabular}{|c|c|c|c|}
\hline $\begin{array}{c}\text { Grade } 8 \\
\text { learners }\end{array}$ & $\begin{array}{c}\text { OS } \\
\mathrm{f}(\%)\end{array}$ & $\begin{array}{c}\text { CS } \\
\mathrm{f}(\%)\end{array}$ & TOTAL \\
\hline Group 1 & $2352(58 \%)$ & $1728(42 \%)$ & $4080(100 \%)$ \\
\hline Group 2 & $2461(59 \%)$ & $1686(41 \%)$ & $4147(100 \%)$ \\
\hline Group 3 & $829(57 \%)$ & $624(43 \%)$ & $1453(100 \%)$ \\
\hline
\end{tabular}

Table 1. Frequency of obligatory and correct suppliances of morphological markers across three groups of Grade 8 learners (general data).

The findings from Table 1 do not point to major disparities in the frequency of obligatory and correct suppliances in the use of morphological markers across three groups of Grade 8 learners (first part of RQ1) despite roughly half the number of the obtained recordings in the third year of research when compared to the two previous years (see subsection 3.2). Namely, the obligatory suppliance of morphological markers for the first group differed by only $1 \%$ when compared to both the second and the third group. The second group, however, differed by $2 \%$ in comparison to the third group regarding the frequency of obligatory suppliance of the morphological markers. Furthermore, no greater differences in the correct suppliance of morphological markers were found across the three groups of learners. The third group of Grade 8 learners appears to have correctly supplied the markers most frequently $(43 \%)$. These learners provided by $2 \%$ more correct suppliance in the use of morphological markers than the second group (41\%) and by $1 \%$ more in regard to the first group $(42 \%)$.

Since the results in Table 1 only partially account for the suppliance of morphological markers as they manifest general data, a more detailed insight into the frequency of their suppliance is gained by examining the distribution of obligatory and correct occurrences for each morpheme under study. The results on the distribution of obligatory and correct suppliances are revealed in Table 2 (second part of RQ1). However, these results will be examined only regarding the distribution of correct suppliance in the use of morphological markers due to several reasons which made the distribution of obligatory suppliance quite difficult to investigate. These detailed reasons will be discussed later.

\begin{tabular}{|l|c|c|c|c|c|c|}
\hline \multirow{3}{*}{ Marker } & \multicolumn{5}{|c|}{ Grade 8 learners } \\
\cline { 2 - 7 } & \multicolumn{2}{|c|}{ Group 1 } & \multicolumn{2}{c|}{ Group 2 } & \multicolumn{2}{c|}{ Group 3 } \\
\cline { 2 - 7 } & OS f $(\%)$ & CS f $(\%)$ & OS f $(\%)$ & CS f $(\%)$ & OS f (\%) & CS f $(\%)$ \\
\hline$-s$ & $157(7 \%)$ & $110(6 \%)$ & $198(8 \%)$ & $113(7 \%)$ & $82(10 \%)$ & $42(7 \%)$ \\
\hline
\end{tabular}




\begin{tabular}{|l|c|c|c|c|c|c|}
\hline $\begin{array}{l}\text { auxiliary } \\
\text { verb be }\end{array}$ & $24(1 \%)$ & $19(1 \%)$ & $60(2 \%)$ & $44(3 \%)$ & $20(2 \%)$ & $14(2 \%)$ \\
\hline- ing & $24(1 \%)$ & $19(1 \%)$ & $60(2 \%)$ & $40(2 \%)$ & $20(2 \%)$ & $16(3 \%)$ \\
\hline $\begin{array}{l}\text { past regular } \\
(- \text { ed })\end{array}$ & $289(12 \%)$ & $181(10 \%)$ & $324(13 \%)$ & $164(10 \%)$ & $71(9 \%)$ & $37(6 \%)$ \\
\hline past irregular & $869(37 \%)$ & $580(34 \%)$ & $958(39 \%)$ & $577(34 \%)$ & $232(28 \%)$ & $145(23 \%)$ \\
\hline $\begin{array}{l}\text { auxiliary } \\
\text { verb have }\end{array}$ & $152(6 \%)$ & $107(6 \%)$ & $9(0 \%)$ & $2(0 \%)$ & $8(1 \%)$ & $3(0 \%)$ \\
\hline- -en & $152(6 \%)$ & $93(5 \%)$ & $9(0 \%)$ & $2(0 \%)$ & $8(1 \%)$ & $5(1 \%)$ \\
\hline $\begin{array}{l}\text { be } \\
\text { (am, are, is) }\end{array}$ & $335(14 \%)$ & $321(19 \%)$ & $506(21 \%)$ & $477(28 \%)$ & $255(31 \%)$ & $253(41 \%)$ \\
\hline $\begin{array}{l}\text { be } \\
\text { (was, were) }\end{array}$ & $350(15 \%)$ & $298(17 \%)$ & $337(14 \%)$ & $267(16 \%)$ & $133(16 \%)$ & $109(17 \%)$ \\
\hline
\end{tabular}

Table 2. Distribution of obligatory and correct suppliance of morphological markers across three groups of Grade 8 learners.

The two most frequently supplied markers regarding their correct use across three different generations of Grade 8 learners are the past irregular and the present tense copula be (Table 2). First in frequency of the correct suppliance for both the first and the second group is the past irregular which is equally distributed between the two generations (34\%). However, the first in frequency for the third group is the present tense copula be accounting for $41 \%$ of its correct suppliance. Second in frequency across the first and the second generation of Grade 8 learners is the correct suppliance of the present tense copula be occurring by $9 \%$ more frequently among the learners of the second generation (19\% for the first group, $28 \%$ for the second group). Furthermore, the third in frequency is the past tense copula be exhibiting $17 \%$ of the correct suppliance for the first and the third group whereas the second group correctly supplied the same marker slightly lower (16\%).

It is interesting to point out that the frequency of correct suppliance for the past regular follows the same pattern of occurrence as observed in the suppliance of the past irregular among Grade 8 learners of the first and the second group. Namely, both groups correctly supplied the past regular by $10 \%$ while the third group provided only $6 \%$ of its correct suppliance.

When observing the frequency of correct suppliance for the third person singular, it can be stated that its use was almost equally distributed across all three generations of Grade 8 learners (6\% for the first group, $7 \%$ for both the second and the third group). Moreover, the correct suppliance of this marker even more frequently occurs than the correct suppliance of either the auxiliary verb be or the present participle across all three generations of Grade 8 learners.

Although the frequency of correct suppliance in the use of component parts 
constituting Present Continuous is equally distributed among the first group of Grade 8 learners and reaches $1 \%$ for both markers, these learners show the lowest frequency in the correct suppliance of the auxiliary verb be and the present participle with regard to the other two groups. Namely, while the second group of the eighth graders correctly supplied the auxiliary verb be by $3 \%$ and the present participle by $2 \%$, the frequency of correct suppliance for the third group is reversed $(2 \%$ of the correct suppliance for the auxiliary verb be, $3 \%$ for the present participle).

In view of the occurrence of morphological markers forming Present Perfect, it can be stated that only Grade 8 learners of the first group provided correct suppliance for both the auxiliary verb have and the past participle (6\% for the auxiliary verb have, $5 \%$ for the past participle). In the speech production of the second and the third generation no suppliance in the use of these markers has been recorded. The only exception is found among the third group of Grade 8 learners accounting for $1 \%$ of the correct suppliance in the use of the past participle which is most probably due to incorrect coding since the past participle and the past irregular frequently overlap in form.

\subsection{Results on the orders of the emergence of morphological markers}

Based on the data in Table 2, the orders of the emergence of morphological markers for each group of Grade 8 learners (first part of RQ2) were determined. The obtained orders are reported in separate tables. Correlations between the orders of the emergence of morphological markers for both methods are portrayed under each table. Following these results are the correlations revealing the differences/similarities in the obtained orders across three groups of Grade 8 learners (second part of RQ2).

\begin{tabular}{|l|c|c|c|c|}
\hline \multicolumn{1}{|c|}{$\begin{array}{c}\text { Method/Rank } \\
\text { Marker }\end{array}$} & $\begin{array}{c}\text { Group means } \\
\text { method (\%) }\end{array}$ & Rank & $\begin{array}{c}\text { Group score } \\
\text { method (\%) }\end{array}$ & Rank \\
\hline$-S$ & 69.9 & 6 & 70.1 & 6 \\
\hline auxiliary verb be & 83.3 & 2 & 79.2 & 3 \\
\hline -ing & 75.0 & 5 & 79.2 & 3 \\
\hline past regular (-ed) & 58.6 & 9 & 62.6 & 8 \\
\hline past irregular & 63.5 & 8 & 66.7 & 7 \\
\hline auxiliary verb have & 77.9 & 4 & 70.4 & 5 \\
\hline past participle (-en) & 63.7 & 7 & 61.2 & 9 \\
\hline be (am, are, is) & 96.2 & 1 & 95.8 & 1 \\
\hline be (was, were) & 83.3 & 2 & 85.1 & 2 \\
\hline
\end{tabular}

Table 3. Order of emergence of morphological markers for the first group Of Grade 8 learners; $\mathrm{r}_{\mathrm{gs}, \mathrm{gm}} 8{ }_{1}=0.9 ; \mathrm{p}<.05, \mathrm{p}<.01$. 
The two highest accuracy scores attained for the first group of Grade 8 learners were the present tense copula be $(95.8 \%)$ and the past tense copula be $(85.1 \%)$ (Table $3)$. In the case of emergence of the markers constituting Present Continuous among these learners, it cannot be claimed with certainty which of the two morphemes, the auxiliary verb be or the present participle, emerged earlier since both of them reached the same accuracy score $(79.2 \%)$.

However, according to the group means method, which was a secondary research method of this study, it can be stated that the auxiliary verb be seems to have emerged prior to the present participle. Namely, the first generation of Grade 8 learners displayed an accuracy score of $83.3 \%$ for the auxiliary verb be and an accuracy score of $75 \%$ for the present participle. Additionally, examining the use of the present participle and the third person singular in the verbal behaviour of the first generation, it appears that the emergence of the present participle with an accuracy score of $79.2 \%$ preceded the emergence of the third person singular which resulted with $9.1 \%$ lower accuracy score.

Furthermore, the first group of learners yielded a slightly higher accuracy score in the use of the past irregular $(66.7 \%)$ with regard to the score obtained for the past regular $(62.6 \%)$ thus providing the past irregular with a higher rank of emergence. In view of the emergence of Present Perfect, the auxiliary verb have was ranked the fifth $(70.4 \%)$ whereas the past participle was ranked last due to the lowest accuracy score $(61.2 \%)$. In conclusion, Grade 8 learners of the first group exhibited emergent use of present tense copula be, past tense copula be, auxiliary verb be, present participle, auxiliary verb have, $-s$, past irregular, past regular, past participle, in that order.

\begin{tabular}{|l|c|c|c|c|}
\hline \multicolumn{1}{|c|}{$\begin{array}{c}\text { Method/Rank } \\
\text { Marker }\end{array}$} & $\begin{array}{c}\text { Group means } \\
\text { method (\%) }\end{array}$ & Rank & $\begin{array}{c}\text { Group score } \\
\text { method (\%) }\end{array}$ & Rank \\
\hline$-s$ & 62.3 & 6 & 57.1 & 6 \\
\hline auxiliary verb be & 79.4 & 2 & 73.3 & 3 \\
\hline- ing & 68.8 & 4 & 66.7 & 4 \\
\hline past regular (-ed) & 56.5 & 7 & 50.6 & 7 \\
\hline past irregular & 65.5 & 5 & 60.2 & 5 \\
\hline auxiliary verb have & & & & 1 \\
\hline past participle (-en) & 93.8 & 1 & 94.3 & 2 \\
\hline be (am, are, is) & 74.2 & 3 & 79.2 & \\
\hline be (was, were) & & & & \\
\hline
\end{tabular}

Table 4. Order of emergence of morphological markers for the second group of Grade 8 learners; $\mathrm{r}_{\mathrm{gs}, \mathrm{gm}} 8_{2}=0.9 ; \mathrm{p}<.05, \mathrm{p}<.01$. 
Similarly to the learners of the first group, the second group of Grade 8 learners (Table 4) generated the highest accuracy scores for two markers. The present tense copula be emerged as first since it was used accurately $94.3 \%$ of the time while the past tense copula be emerged in second due to an accuracy score differing from the former morpheme by $15.1 \%$ (79.2\% for the past tense copula $b e)$.

The second generation, furthermore, disclosed antecedent emergence in the use of the auxiliary verb be in comparison to the emergence of the present participle. Namely, the accuracy score for the auxiliary verb be was $73.3 \%$ whilst for $-i n g 66.7 \%$. Moreover, the present participle emerged before $-S$ which, analogously to the first generation of Grade 8 learners (Table 3), was positioned the sixth in rank. However, the accuracy score attained for the third person singular $-S$ within the second generation was $13 \%$ lower regarding the score for the same marker attained among the first generation of Grade 8 learners (Table 3) (70.1\% for the first group, $57.1 \%$ for the second group).

Also, the past irregular was higher in rank (positioned the fifth), thus emerging earlier when compared to the past regular owing to its $60.2 \%$ score whereas the latter marker with $50.6 \%$ in accuracy was lower in rank (positioned the seventh). With respect to the emergence of two markers in the use of Present Perfect, no results were obtained due to the lack of their suppliance in the classroom talk of the second generation of learners (Table 2). Finally, the second group of Grade 8 learners unveiled the following order of emergence: present tense copula be, past tense copula $b e$, auxiliary verb $b e$, present participle, past irregular, third person singular $-s$ and past regular.

\begin{tabular}{|l|c|c|c|c|}
\hline \multicolumn{1}{|c|}{$\begin{array}{c}\text { Method/ Rank } \\
\text { Marker }\end{array}$} & $\begin{array}{c}\text { Group means } \\
\text { method (\%) }\end{array}$ & Rank & $\begin{array}{c}\text { Group score } \\
\text { method (\%) }\end{array}$ & Rank \\
\hline$-s$ & 53.8 & 5 & 51.2 & 7 \\
\hline auxiliary verb be & 87.5 & 2 & 70.0 & 4 \\
\hline- ing & 87.5 & 2 & 80.0 & 3 \\
\hline past regular (-ed) & 40.9 & 7 & 52.1 & 6 \\
\hline past irregular & 51.1 & 6 & 62.5 & 5 \\
\hline auxiliary verb have & & & & 1 \\
\hline past participle (-en) & 99.6 & 1 & 99.2 & 2 \\
\hline be (am, are, is) & 83.2 & 4 & 82.0 & \\
\hline be (was, were) & & & & \\
\hline
\end{tabular}

Table 5. Order of emergence of morphological markers for the third group of Grade 8 learners; $r_{g s, g m} 8{ }_{3}=0.8 ; p<.05, p<.01$. 
As with the previous generations of Grade 8 learners, the third generation (Table 5 ) most accurately used the present and the past tense copula be. These markers, thus, emerged first and second in the speech production of this group exhibiting almost $100 \%$ in accuracy for the present tense copula be with a considerably lower score in accuracy attained for the past tense copula be $(82 \%)$.

Surprisingly, unlike the first and the second group, Grade 8 learners of the last group demonstrated earlier emergent use of the present participle over the auxiliary verb be. Namely, the use of the present participle exceeded by $10 \%$ in accuracy the use of the auxiliary verb be ( $80 \%$ for the present participle, $70 \%$ for the auxiliary verb $b e$ ). However, regarding the use of -ing and $-s$, this group of learners seems to follow the same order of emergence as the learners of both previous generations. Being positioned third, the present participle manifested prior emergent use when compared to the third person singular $-S$ which was positioned seventh due to the $51.2 \%$ accuracy score.

What is more, the results from the above table indicate that emergent use of the past regular occurs after the past irregular because of the lower accuracy score for the former marker (52.1\%) when compared to the score of the latter morpheme $(62.5 \%)$. Also, the results on the order of emergence of two markers forming Present Perfect resemble the results obtained for the previous generation (Table 4). Namely, no ranking order was determined for these morphemes due to the absence of examples of their use among the learners of the third group. To sum, the markers used among Grade 8 learners of the third group emerged in the following order: present tense copula be, past tense copula be, present participle, auxiliary verb be, past irregular, past regular and third person singular $-s$.

The correlations of orders of the emergence of morphological markers obtained by both methods are remarkably high, as indicated by the Spearman correlation coefficients. Namely, the orders of emergence correlated significantly at the .01 level ( $\mathrm{r}=0.9$ for both first and second group) and at the .05 level ( $\mathrm{r}=0.8$ for the third group). Moreover, the orders of the emergence of morphological markers obtained only by the group score method between the first and the second group of Grade 8 learners reached statistical significance at the .01 level $(\mathrm{r}=0.96)$, between the first and the third group at the 0.1 level $(\mathrm{r}=0.88)$ and, finally, between the second and the third group at the .01 level $(\mathrm{r}=0.93)$. These results indicate that there is a similar order of the emergence of morphological markers across three groups of Grade 8 learners.

\subsection{Results on the order of the emergence of verb tenses}

Due to statistically insignificant correlations in the obtained orders of the emergence of tenses between different groups of Grade 8 learners, the order of emergence of verb tenses (RQ3) was established for a larger sample size (see subsection 3.5). 


\begin{tabular}{|l|c|c|}
\hline \multicolumn{1}{|c|}{ Method/Rank } & Group score method (\%) & Rank \\
\hline Simple Present & 85.8 & 1 \\
\hline Present Continuous & 73.1 & 2 \\
\hline Simple Past & 66.2 & 3 \\
\hline Present Perfect & 62.7 & 4 \\
\hline
\end{tabular}

Table 6. Order of emergence of verb tenses across three groups of Grade 8 learners

The first tense to emerge in the interlanguage of Grade 8 learners is Simple Present with the highest accuracy score (85.8\%) (Table 6). The pattern of high accuracy score (73.1\%) persists also for Present Continuous whereas the two remaining tenses, Simple Past and Present Perfect, marked lower scores. Namely, both Simple Past and Present Perfect exhibited approximately a 21\% lower score when compared to the score obtained for the tense positioned first (by 19.6\% lower score for Simple Past and by $23.1 \%$ for Present Perfect) and by $9 \%$ lower in comparison to the accuracy score attained for the tense positioned second in rank (by 6.9\% lower score for Simple Past and by $10.4 \%$ for Present Perfect). Thus, the resulting order of the emergence of tenses across three different groups of the eighth graders is: Simple Present, Present Continuous, Simple Past and Present Perfect.

\section{Discussion}

The results are discussed in accordance with the study questions in the subsections that follow.

\subsection{Suppliance and distribution of obligatory and correct occurrences in the use of morphological markers}

As stated earlier in subsection 5.1, the distribution of the obligatory suppliance of morphological markers was more challenging to examine due to the influence of diverse factors. First, the number of learners in each year of research varied which seems to have effected obligatory suppliance of morphological markers over the observation period. Namely, more learners most probably presupposes more obligatory contexts thus making obligatory suppliance of morphological markers unequally distributed across the three groups of learners. Second, it occasionally occurred that the samples of EFL classroom dialogue originated from the same few learners whose speech production prevailed throughout the entire recording session although it was another learner's turn to speak. In these situations the learner's speech performance might have abounded with more obligatory suppliance in the use of a particular marker over the obligatory suppliance of another one. Furthermore, in situations when the selection of communicative activity was entirely up to the learners since their participation in this study was non-mandatory (see subsection 3.3), the type of the activity might have affected the suppliance of markers in obligatory contexts as 
some of the task-based activities promoted more frequent suppliance of only a few morphemes. For instance, the activity always starting with the same question exclusively focused on the use of the past regular and the past irregular thus resulting in more obligatory suppliance in their use. Third, the length of recordings, although set at approximately 15 minutes, varied since the learners were allowed to extend their speech production until reaching a communicative goal which, most probably, caused differences in the frequency of obligatory suppliance in the use of markers across three groups of Grade 8 learners.

\subsection{Order of the emergence of morphological markers}

When comparing the results on the suppliance of the morphological markers (Table 2) with the orders of emergence obtained for three groups of Grade 8 learners (Table 3, Table 4, Table 5), it appears that although the first in frequency of the correct suppliance, surprisingly, the past irregular wasn't ranked the first neither among the first nor the second group. The first to emerge for both groups, however, was the present tense copula be which was the second in frequency of the correct suppliance. Following this marker is the past tense copula be occupying the second position in the ranking order of both the first and the second group with even lower percentage of the correct suppliance when compared to the past irregular and the present tense copula be. Regardless of these results, the third group, interestingly, displayed reverse results. The last generation of Grade 8 learners exhibited the highest percentage of the correct suppliance for the present tense copula be which accordingly was ranked first. Since the copula be indicating both the present and the past ranked the first and the second at the top across all three groups thus emerging prior to auxiliary be which was subsequently followed by the present participle, it might be suggested that these results coincide with the morpheme ordering studies (H.C. Dulay/ M.K. Burt 1973/ N. Bailey et al. 1974, P. Widiatmoko 2008, U.F. Ibáñez 2013).

Similarly to the previous morpheme order findings related not only to L1 acquisition (R. Brown 1973, J. de Villiers/ P. de Villiers 1973) but also to L2 acquisition (H.C. Dulay/ M.K. Burt 1973, N. Bailey et al. 1974, W. Klein 1995), it seems that all generations of Grade 8 learners acquire -ing prior to $-s$. Namely, the present participle emerged as third among both the first (Table 3 ) and the third group (Table 5) and as fourth among the second group (Table 4) of Grade 8 learners whereas $-S$ emerged as sixth in both the first (Table 3) and the second group (Table 4) of the eighth graders, i.e. the seventh in the last group (Table 5). Furthermore, all three Grade 8 generations unanimously confirmed that the past irregular emerges before the past regular and thus supported the third principle regarding the acquisition of tense-aspect morphology expressing temporality (K. Bardovi-Harlig 2000).

In view of the order of emergence of the markers constituting compound verb tenses, Present Continuous and Present Perfect, the results were inconclusive. Even though the emergent use of the markers forming Present Continuous by the third group of Grade 8 learners (Table 5) began with the present participle subsequently followed by the auxiliary verb thus complying with the fourth principle of tense-aspect morphological acquisition of temporality (K. Bardovi-Harlig 2000), the same does not 
apply for the second group (Table 4). Besides, the same pattern of emergence as the one shown by the second Grade 8 generation in the use of these markers was found among the first generation (Table 3); namely that the auxiliary verb emerges before the present participle when observed by the group means method due to the same ranking order obtained by the group score method.

Unlike the second and the third group of Grade 8 learners, only the first group supplied the morphemes forming Present Perfect (Table 2). The only exception found was a strikingly low amount of correct suppliance in the use of the past participle (1\%) displayed by the third generation of Grade 8 learners, which most probably was the product of incorrect coding owing to, in most cases, the resemblance in form with the past irregular. Since the auxiliary verb have emerged before the past participle in the verbal production of the first generation (Table 3), it might be observed that these learners do not favour the principle according to which the verb with verbal suffix precedes the acquisition of the auxiliary verb (K. Bardovi-Harlig 2000). However, these findings should be interpreted with caution seeing that no ranking orders were provided or the remaining groups (Table 4 and Table 5). In summary, despite all the previously stated discrepancies in the ranking orders of the selected morphemes, it statistically seems that there is a similar order of the emergence of morphological markers across three groups of Grade 8 learners as indicated by the Spearman rank order correlations.

\subsection{Order of the emergence of verb tenses}

According to the obtained findings (Table 6) it might be claimed that the first temporal morphology in the interlanguage of Croatian Grade 8 learners across all generations marks the use of Simple Present prior to the emergent use of Present Continuous. Furthermore, Present Continuous seems to be the first compound tense to emerge. The emergence of Present Perfect appears to depend on the prior emergence of Simple Past which is in accordance with the results of the previous empirical studies (K. Bardovi-Harlig 1997, 2000).

\section{Conclusion}

The aim of this study was to document the acquisition of temporal expression examining the patterns of emergent use of both grammatical morphemes and verb tenses in the speech production across three generations of Croatian Grade 8 learners of English. The study findings have pointed to several conclusions.

Although the order of emergence of the morphological markers expressing temporality across all groups of Grade 8 learners seems to be uniform from the statistical point of view, however, there appears to be variability in the ranking orders of these morphemes when investigating three groups of learners separately. This interlanguage variability is of no surprise since it was, very likely, caused by many different, yet, related factors. The suppliance of markers was determined, on the one hand, by the number of learners and by the type of elicitation task on the other hand, both of which varied. Namely, in each generation there seemed to be a few learners more speech productive than their colleagues thus resulting with more frequent 
suppliance in the use of particular markers of temporality the choice of which most probably depended on their learning style along with some other affective components (motivation, self-esteem, risk-taking). In some situations, furthermore, the selection of communicative activities reflected the learners' interests thus presumably effecting the frequency of suppliance of the morphemes since particular activities elicited the use of specific markers of temporality. In the light of these findings, it might be concluded that the acquisition of target-like tense-aspect markers should be expanded to include the impact of turn-taking, the influence of affective factors and the type of the elicitation task on the order of emergent use of the grammatical morphemes. Additionally, the research could also be expanded to include different proficiency levels within each group gathering a smaller sample of learners which might presumably provide more reliable results on the ranking orders of the grammatical morphemes.

Despite having determined the orders of emergence for both morphological markers and verb tenses which were conditioned by the parameters set forth in the current study, i.e. their selection, it needs to be emphasised that these orders do not suggest that the acquisition of L2 English verbal morphology is over. It rather reveals a stage in interlanguage development, in this case, of L1 learners of Croatian who slowly approximate towards L2 English. In order to fully understand how the process of acquisition evolves, a much wider range of tense-aspect morphology expressing the present-past-future-time should be included in further research or, possibly, the acquisition of verbal morphology with temporal reference should be investigated separately.

\section{References}

Bailey, N. (1987), The importance of meaning over form in second language system building: An unresolved issue. Unpublished doctoral dissertation. New York.

Bailey, N./ C. Madden/ S. Krashen (1974), Is there a "natural sequence" in adult second language learning? In: Language learning 24 (2), 235-243.

Bardovi-Harlig, K. (1997), Another Piece of the Puzzle, The Emergence of the Present Perfect. In: Language Learning 47(3), 375-422.

Bardovi-Harlig, K. (1999), From Morpheme Studies to Temporal Semantics, TenseAspect Research in SLA. In: Studies in Second Language Acquisition 21 (3), 341382.

Bardovi-Harlig, K. (2000), Tense and Aspect in Second Language Acquisition, Form, Meaning and Use. Oxford.

Bardovi-Harlig, K. (2004), The Emergence of Grammaticalized Future Expression in Longitudinal Production Data. In: B. Van Patten/ J. Williams/ S. Rott/ M. Overstreet (eds.), Form-Meaning Connections in Second Language Acquisition. Mahwah, NJ, 123-147.

Barrot, J./ K. de Leon (2014), Accuracy Order of the Grammatical Morphemes in the Oral production of Preschool Pupils. In: Indonesian Journal of Applied Linguistics 3 (2), 63-76. 
Behjat, F. / F. Sadighi (2011), The Acquisition of English Grammatical Morphemes, A Case study of Iranian EFL Learners. MJAL 3 (2), 105-123.

Brown, R. (1973), A First Language. Harvard.

Council of Europe (2001), Common European Framework of Reference for Languages, Learning, Teaching, Assessment. Cambridge.

Croatian Ministry of Science, Education and Sports (2011), Creational national curriculum. Date of access: 15.05.2017. http, //public.mzos.hr/Default.aspx?sec=2501.

Dietrich, R./ W. Klein/ C. Noyau (1995), The acquisition of temporality in a second language. Amsterdam.

De Villiers, J./ P. de Villiers (1973), A cross-sectional study of the acquisition of grammatical morphemes in child speech. In: Journal of Psycholinguistic Research 2, 267-278.

Dulay, H.C. / M.K. Burt (1973), Should we teach children syntax? In: Language Learning 23 (2), 245-258.

Dulay, H.C./ M.K. Burt (1974), Natural sequence in child second language acquisition. In: Language Learning 24, 37-53.

Edwards, J.A. (2001), The transcription of discourse. In: D. Schiffin/ D. Tannen/ H.E. Hamilton (eds.), The handbook of discourse analysis. Malden, MA, 321348.

Ellis, R./ G. Barkhuizen (2005), Analysing Learner Language. Oxford.

Hakuta, K. (1974), A Preliminary report on the development of grammatical morphemes in a Japanese girl learning English as a second language. In: Working Papers in Bilingualism 3, 18-43.

Harmer, J. (2007), The Practice of English Language Teaching. London.

Ibáñez, Ú.F. (2013), A morpheme order study based on an EFL learner corpus, A focus on the Dual mechanism. MA Dissertation. University of Granada.

Klein, W./ D. Rainer/ C. Noyau (1988), The acquisition of temporality. In: M. Bhardwaj/ R. Dietrich/ C. Noyau (eds.) Temporality (Vol. 5 of the Final Report to the ESF). Strasbourg, 73-118.

Klein, W. (1995), The acquisition of English. In: R. Dietrich/ W. Klein/ C. Noyau (eds.) The acquisition of temporality in a second language. Amsterdam, 31-70.

Krashen, S.D. (1977), Some issues related to the monitor model. In: H. Brown/ C. Yorio/ R. Crymes (eds.), On TESOL '77. Washington DC, 144-158.

Larsen-Freeman, D. (1975), The Acquisition of Grammatical Morphemes by Adult Learners of English as a Second Language. Doctoral Thesis. University of Michigan.

Parrott, M. (1993), Tasks for Language Teachers. A Resource Bookfor Training and Development. Cambridge.

Ur, P. (1992), Five-Minute Activities. Cambridge.

Widiatmoko, P. (2008), Grammatical Morpheme Acquisition. An Analysis of an EFL Learner's Language Samples. In: Jurnal Sastra Inggris 8 (1), 22-37. 